\title{
A structural mapping of mutations causing succinyl-CoA: 3-ketoacid CoA transferase (SCOT) deficiency
}

\author{
Naeem Shafqat • Kate L. Kavanagh • Jörn Oliver Sass • \\ Ernst Christensen - Toshiyuki Fukao • Wen Hwa Lee • \\ Udo Oppermann - Wyatt W. Yue
}

Received: 30 May 2012 /Revised: 14 January 2013 / Accepted: 15 January 2013 /Published online: 19 February 2013

(C) The Author(s) 2013. This article is published with open access at Springerlink.com

\begin{abstract}
Succinyl-CoA:3-ketoacid CoA transferase (SCOT) deficiency is a rare inherited metabolic disorder of ketone metabolism, characterized by ketoacidotic episodes and often permanent ketosis. To date there are $\sim 20$ disease-associated alleles on the OXCT1 gene that encodes the mitochondrial enzyme SCOT. SCOT catalyzes the first, rate-limiting step of ketone body utilization in peripheral tissues, by transferring a CoA moiety from succinyl-CoA to form acetoacetyl-CoA, for entry into the tricarboxylic acid cycle for energy production. We have determined the crystal structure of human SCOT, providing a molecular understanding of the reported mutations based on their potential structural effects. An interactive version of this manuscript (which may contain additional mutations appended after acceptance of this manuscript) may be found on the web address: http://www.thesgc.org/jimd/SCOT.
\end{abstract}

Communicated by: Johannes Zschocke

Database reference OMIM, 245050; GenBank, 4557817; URL, http://www.thesgc.org/SCOT; PDB code, 3DLX

Electronic supplementary material The online version of this article (doi:10.1007/s10545-013-9589-z) contains supplementary material, which is available to authorized users.

N. Shafqat · K. L. Kavanagh • W. H. Lee · U. Oppermann •

W. W. Yue $(\bowtie)$

Structural Genomics Consortium, University of Oxford,

Oxford OX3 7DQ, UK

e-mail: wyatt.yue@sgc.ox.ac.uk

J. O. Sass

Zentrum für Kinder- und Jugendmedizin, Universitätsklinikum

Freiburg, 79106 Freiburg, Germany

J. O. Sass

Klinische Chemie \& Biochemie, Universitäts-Kinderspital,

8032 Zürich, Switzerland

E. Christensen

Department of Clinical Genetics, Juliane Marie Centre,

2100 Copenhagen, Denmark

\begin{abstract}
Abbreviations
SCOT Succinyl-CoA:3-ketoacid CoA transferase

OXCT1 3-oxoacid CoA transferase 1
\end{abstract}

\section{Introduction}

Ketone bodies (acetoacetate, 3-hydroxybutyrate, acetone), predominantly produced in the liver, provide extrahepatic organs such as heart and brain with energy when glucose supply is limited (Sass 2012). Any enzyme malfunction in ketone body utilization (ketolysis) could lead to a buildup of unused ketone bodies and result in ketoacidosis. SuccinylCoA:3-ketoacid CoA transferase (SCOT; gene name OXCT1; EC 2.8.3.5) catalyzes the first and rate-determining

\author{
T. Fukao \\ Department of Pediatrics, Graduate School of Medicine, \\ Gifu University, Gifu 501-1194, Japan
}

T. Fukao

Medical information Sciences Division, United Graduate School of Drug Discovery and Medical Information Sciences, Gifu University, Gifu 501-1194, Japan

U. Oppermann

Botnar Research Centre, Oxford Biomedical Research Unit, OX3 7LD Oxford, UK 
step of ketolysis (Fukao et al 2000; Kassovska-Bratinova et al 1996). SCOT is a member of the CoA transferase family I that activates acetoacetate by transferring a CoA moiety from succinyl-CoA to form acetoacetyl-CoA. Acetoacetyl-CoA is further metabolized by acetoacetyl-CoA thiolase into two acetyl-CoA molecules which enter the citric acid cycle for energy production (Williamson et al 1971). SCOT is a mitochondrial enzyme expressed in all extrahepatic tissues, but abundant in the heart, brain and kidney (Fukao et al 1997). There exists also a testis-specific isoform SCOT-t (gene name OXCT2), sharing $74 \%$ amino acid identity with SCOT (Tanaka et al 2002).

Mutations in the human OXCT1 gene on chromosome location $5 \mathrm{p} 13$ result in the rare autosomal recessive deficiency of SCOT (OMIM 245050) (Mitchell and Fukao 2001). SCOT- deficient patients, often with neonatal onset, present with recurrent ketoacidosis episodes that could be life-threatening, but with no symptoms between episodes (Niezen-Koning et al 1997). The number of reported cases is few, and symptoms, which may vary among individuals, include vomiting, lethargy and tachypnea, as well as unconsciousness caused by severe ketoacidosis (Berry et al 2001; Sakazaki et al 1995; Snyderman et al 1998). Permanent ketosis or ketonuria is a characteristic symptom but may be absent in patients retaining residual SCOT activity (Fukao et al 2010; Fukao et al 2011; Fukao et al 2004). Approximately 30 affected probands were reported to date and 24 mutations identified (Table 1). Here we report the crystal structure of human SCOT, and present an interactive mapping of missense mutations to understand the molecular basis of SCOT deficiency.

Table 1 Mutations reported for the human OXCT1 gene causing SCOT deficiency. Additional phenotype information can be found in the supplementary text

\begin{tabular}{|c|c|c|c|c|c|c|c|}
\hline \# & DNA change & Exon & Mutation site & $\begin{array}{l}\text { Mutated } \\
\text { residue }\end{array}$ & Protein change & Conservation & Reference \\
\hline $1^{\mathrm{a}, \mathrm{c}, \mathrm{d}}$ & c. $112 \mathrm{C}>\mathrm{T}^{\mathrm{b}}$ & 2 & $\operatorname{Arg} 38$ & Cys & p.R38C & & (Alkén 2008) \\
\hline $2^{\mathrm{c}}$ & c. $335 \mathrm{~T}>\mathrm{A}^{\mathrm{b}}$ & 4 & Val112 & Asp & p.V112D & Semi-Conserved & (Alkén 2008) \\
\hline 3 & c. $398 \mathrm{~T}>\mathrm{A}$ & 4 & Val133 & Glu & p.V133E & Semi-Conserved & (Song et al 1998) \\
\hline 4 & c. $644 \mathrm{C}>\mathrm{T}$ & 6 & Ala215 & Val & p.A215V & Conserved & (Fukao et al 2011) \\
\hline 5 & c. $656 \mathrm{G}>\mathrm{A}$ & 6 & Gly219 & Glu & p.G219E & Conserved & (Fukao et al 2000) \\
\hline 6 & c. $661 \mathrm{G}>\mathrm{A}$ & 6 & Val221 & Met & p.V221M & Semi-Conserved & (Fukao et al 2000) \\
\hline 7 & c. $677 \mathrm{G}>\mathrm{A}$ & 7 & Ser226 & Asn & p.S226N & Semi-Conserved & (Fukao et al 2011) \\
\hline $8^{\mathrm{c}}$ & c. $785 \mathrm{C}>\mathrm{G}$ & 8 & Pro262 & Arg & p.P262R & Conserved & Sass et al (unpublished) \\
\hline $9^{c}$ & c. $802 \mathrm{C}>\mathrm{T}$ & 8 & $\operatorname{Arg} 268$ & Cys & p.R268C & Conserved & Sass et al (unpublished) \\
\hline 10 & c. $803 \mathrm{G}>\mathrm{A}$ & 8 & $\operatorname{Arg} 268$ & His & p.R268H & Conserved & (Fukao et al 2007) \\
\hline 11 & c. $971 \mathrm{G}>\mathrm{A}$ & 10 & Gly324 & Glu & p.G324E & Conserved & (Fukao et al 2000) \\
\hline 12 & c. $980 \mathrm{~T}>\mathrm{C}$ & 10 & Leu327 & Pro & p.L327P & Conserved & (Fukao et al 2011) \\
\hline $13^{\dagger}$ & c. $1162 A>G^{b}$ & 12 & Met388 & Val & p.M388V & Conserved & (Alkén 2008) \\
\hline 14 & c. $1210 \mathrm{G}>\mathrm{T}$ & 13 & Val404 & Phe & p.V404F & Conserved & (Fukao et al 2011) \\
\hline 15 & c. $1213 \mathrm{~T}>\mathrm{C}$ & 13 & Ser405 & Pro & p.S405P & Conserved & (Fukao et al 2011) \\
\hline $16^{\dagger \dagger}$ & $\mathrm{b}$ & 14 & Leu429 & Phe & p.L429F & Conserved & (Alkén 2008) \\
\hline 17 & c. $1304 \mathrm{C}>\mathrm{A}$ & 14 & Thr435 & Asn & p.T435N & Conserved & $\begin{array}{l}\text { (Fukao et al 2010; } \\
\text { Fukao et al 2004) }\end{array}$ \\
\hline 18 & c. $1367 \mathrm{G}>\mathrm{T}$ & 15 & Cys456 & Phe & p.C456F & Conserved & (Song et al 1998) \\
\hline 19 & c. $1402 \mathrm{C}>\mathrm{T}$ & 15 & $\operatorname{Arg} 468$ & Cys & p.R468C & Low-conserved & (Fukao et al 2011) \\
\hline \multicolumn{8}{|c|}{ Insertion, deletion, frameshift mutations } \\
\hline 20 & c. $649 \mathrm{C}>\mathrm{T}$ & 6 & $\operatorname{Arg} 217$ & $\mathrm{X}$ & p.R217X & Semi-Conserved & (Longo et al 2004) \\
\hline 21 & c. $817 \mathrm{G}>\mathrm{T}$ & 8 & Glu273 & $\mathrm{X}$ & p.E273X & Variable & (Fukao et al 2011) \\
\hline 22 & c. $848 \mathrm{C}>\mathrm{G}$ & 9 & Ser283 & $\mathrm{X}$ & p.S283X & Conserved & (Yamada et al 2007) \\
\hline 23 & c.658-666dup & 6 & Asn220-Ile222 & & p.N220-I222 dup & $\begin{array}{l}\text { Conserved (Asn220), } \\
\text { Semi-conserved (Val221,Ile222) }\end{array}$ & (Fukao et al 2010) \\
\hline 24 & c. $1561 \mathrm{~T}>\mathrm{C}^{\mathrm{b}}$ & 6 & $\mathrm{X} 521 \mathrm{R}$ & Arg & Adding 20 AAs & & (Alkén 2008) \\
\hline
\end{tabular}

${ }^{\mathbf{a}}$ The R38C mutation resides in the N-terminus of the protein that is disordered and not modelled in the crystal structure

${ }^{\mathrm{b}}$ DNA change in the R38C, V122D, M388V and X521R mutations are deduced from amino acid substitution. The DNA change in the L429F mutation is not reported and cannot be deduced from amino acid substitution

${ }^{\mathrm{c}}$ These mutations have not been confirmed as pathogenic by expression analysis

${ }^{\mathrm{d}} \mathrm{R} 38 \mathrm{C}$ and L429F mutations coexisted in one mutant allele 
Fig. 1 Ribbon diagram of human SCOT structure illustrating the homodimeric assembly. The two monomeric subunits $\mathbf{a}$ and $\mathbf{b}$ are coloured distinctively (blue and magenta). The active site in each subunit is indicated by the Glu344 residue shown in orange sticks

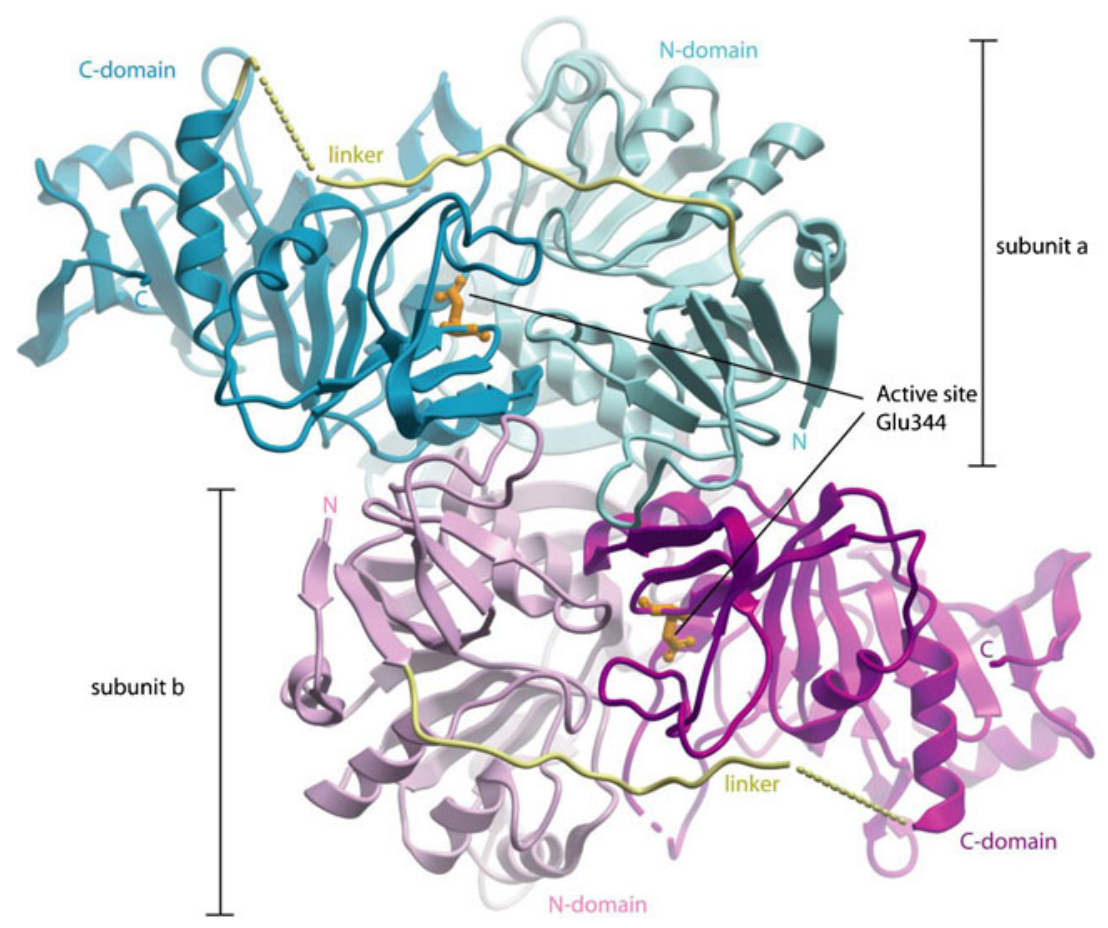

\section{Experimental procedures}

Expression, purification \& crystallization

DNA fragment encoding the catalytic domain of human SCOT (aa 40-520; GenBank entry 4557817) was subcloned into pNIC-CTHF vector incorporating a C-terminal His $_{6-}$ tag. The plasmid was transformed into BL21(DE3)-R3pRARE2, cultured in Terrific Broth at $37{ }^{\circ} \mathrm{C}$, and induced with $0.5 \mathrm{mM}$ IPTG. Cells were homogenized in lysis buffer (50 mM HEPES pH7.5, $500 \mathrm{mM} \mathrm{NaCl}, 5 \%$ glycerol, $5 \mathrm{mM}$ imidazole, $1 \mathrm{mM}$ PMSF, $0.5 \mathrm{mM}$ TCEP), centrifuged to remove cell debris, and the supernatant was purified by Nickel affinity (HisTrap $1 \mathrm{ml} \mathrm{GE/Amersham)} \mathrm{and} \mathrm{size} \mathrm{ex-}$ clusion (HiLoad 16/60 Superdex S200) chromatography. Purified protein was concentrated to $21 \mathrm{mg} / \mathrm{ml}$ and stored in $10 \mathrm{mM}$ HEPES pH7.5, $500 \mathrm{mM} \mathrm{NaCl}, 5 \%$ (w/v) glycerol and $0.5 \mathrm{mM}$ TCEP at $-80{ }^{\circ} \mathrm{C}$. Crystals were grown by vapour diffusion at $20^{\circ} \mathrm{C}$, in sitting drops mixing $100 \mathrm{nl}$ protein pre-incubated with $2 \mathrm{mM}$ acetyl-CoA and $300 \mathrm{nl}$ reservoir solution containing $0.20 \mathrm{M}$ sodium chloride, $0.1 \mathrm{M}$ Tris pH9.0 and $25 \%(\mathrm{w} / \mathrm{v})$ polyethylene glycol 3,350. Crystals were cryo-protected in mother liquor containing $20 \%(\mathrm{w} / \mathrm{v})$ glycerol and flash-frozen in liquid nitrogen.
Fig. 2 Clustering of human SCOT missense mutations, displayed in the same colour scheme as Fig. 1. The positions of amino acid mutations are indicated by small spheres and numbered according to Table 1. Mutations that affect the monomeric fold or dimerization interaction are coloured red and yellow respectively

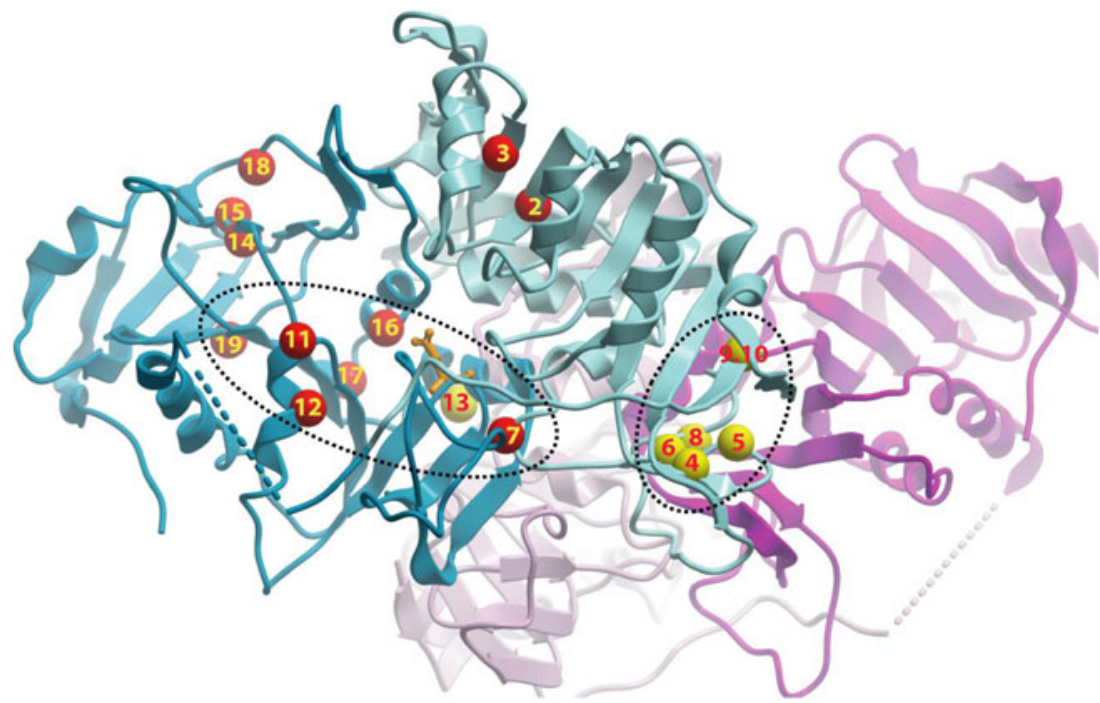


Data collection \& structure determination

Diffraction data to maximum resolution of $2.20 \AA$ were collected on beamline X10A at the Swiss Light Source, and processed using the CCP4 Program suite (CCP4 1994). SCOT crystallized in the $P 2_{1}$ space group with four molecules in the asymmetric unit (Supplementary Table 1). The structure of human SCOT was solved by molecular replacement with PHASER (McCoy et al 2005), using the pig heart structure as search model (PDB code 1M3E)(Bateman et al 2002). Initial automated model building was performed with ARP/wARP (Perrakis et al 2001), followed by cycles of iterative manual model building with COOT (Emsley and Cowtan 2004) and REFMAC5 refinement (Murshudov et al 1997). The refined model consists of protein residues 40-285 and 297-519. No electron density was observed for part of the inter-domain linker (residues 286-296). No ligand density for acetyl-CoA was found in the active site though it was added during crystallization. Structure factors and coordinates were deposited in the Protein Data Bank under the accession code 3DLX.

\section{Results and discussion}

We have determined the crystal structure of human SCOT which exhibits a homodimer architecture containing two active sites (Fig. 1). Each monomer consists of the amino-terminal (N-; aa 40-272) and carboxy-terminal (C-; a 298-510) domains, connected by a linker region (aa 273-297). The Nand C-domains share a common $\alpha / \beta$ structural fold for CoA transferase family I members (Heider 2001), as previously seen in the pig SCOT structure ( $89 \%$ sequence identity)(Bateman et al 2002). The active site of each monomer is situated at the interface of the two domains, where a strictly conserved residue Glu344 (Fig. 1, orange sticks) attacks the incoming succinyl-CoA substrate and forms an enzyme-CoA thioester intermediate, as an integral part of the catalytic mechanism (Solomon and Jencks 1969). Residues in the active site of human SCOT are also conserved in the testis-specific isoform SCOT-t, suggesting it may have enzymatic activity.

To date, three nonsense, two insertion and 19 missense mutations leading to SCOT deficiency are known from literature or newly reported here (Table 1 and Supplementary text), although six missense mutations have not been confirmed as pathogenic mutations by expression analysis. There is a polymorphism c.173C $>\mathrm{T}$ (T58M) which retains full enzyme activity (Song et al 1998). The three nonsense mutations (R217X, E273X, S283X) are expected to cause premature translation termination, resulting in truncated SCOT proteins that lack completely the $\mathrm{C}$-domain and hence abolish part of the active site. Another mutation c. $1561 \mathrm{~T}>\mathrm{C}$ at the termination codon results in X521R and adds 20 amino acids in the $\mathrm{C}$ terminus of SCOT peptide (Alkén 2008). The missense mutations are broadly distributed between the N- and C-domains of the protein, although two clusters of 'mutational hotspots' can be observed (Fig. 2). One cluster is close to the interface between two SCOT subunits in a dimer. A duplication mutation (N220-I222dup) is also present in this region (Fukao et al 2010). The other cluster is located in secondary structure elements that make up the active site and CoA-binding site of the enzyme.

The mapping of missense mutations onto the human SCOT structure allows us to classify their potential structural consequences broadly into three types. In the first type, amino acids tightly packed in the enzyme are substituted to bulkier and/or charged residues (Fig. 2 and Table 1, $\# 2-7,11,14,16,17)$. This likely results in severe steric and electrostatic clashes in the local environment which in turn can compromise severely the folding, architecture and stability of the enzyme. These mutants often result in the more severe phenotype (permanent acidosis), consistent with their much diminished enzyme activity (Fukao et al 2000; Song et al 1998). The second type disrupts the integrity of a secondary structure element, either by introducing a conformationallyrestrained residue (e.g. Pro, Gly) into an $\alpha$-helix $/ \beta$-strand (Fig. 2 and Table 1,\#12,15), or by removing such residues from their critical involvement in a loop/turn segment (Fig. 2 and Table 1, \#8). The third type involves the substitution of arginine residues where their guanidinium side-chains are involved in salt bridge formation. These charged interactions contributed to stabilizing two neighbouring regions in $3 \mathrm{D}$ space that are distant apart in the polypeptide sequence. Substitution of arginine to a weakly positive-charged (Fig. 2 and Table 1,\#10) or uncharged amino acid (Fig. 2 and Table 1, $\# 9,19)$ will abolish these salt bridges. Though retaining partial enzyme activities, these mutant proteins are thermally less stable compared to wild-type (Fukao et al 2007; Fukao et al 2011).

Acknowledgments Help in x-ray data collection at the Swiss Light Source by Frank von Delft is gratefully acknowledged. The Structural Genomics Consortium is a registered charity (Number 1097737) funded by the Canadian Institutes for Health Research, the Canada Foundation for Innovation, Genome Canada through the Ontario Genomic Institute, GlaxoSmithKline, Karolinska Institutet, the Knut and Alice Wallenberg Innovation, Merck and Co., Inc., the Novartis Research Foundation, the Swedish Agency for Innovation Systems, the Swedish Foundation for Strategic Research and the Wellcome Trust.

\section{Conflict of interest None}

Open Access This article is distributed under the terms of the Creative Commons Attribution License which permits any use, distribution, and reproduction in any medium, provided the original author (s) and the source are credited. 


\section{References}

Alkén J (2008) Glucose and ketone body metabolism-with emphasis on ketotic hypoglycemia. Ph.D. Thesis, Karolinska Institutet, Stockholm

Bateman KS, Brownie ER, Wolodko WT, Fraser ME (2002) Structure of the mammalian CoA transferase from pig heart. Biochemistry 41:14455-14462

Berry GT, Fukao T, Mitchell GA, Mazur A, Ciafre M, Gibson J, Kondo N, Palmieri MJ (2001) Neonatal hypoglycaemia in severe succinyl-CoA: 3-oxoacid CoA-transferase deficiency. J Inherit Metab Dis 24:587-595

CCP4 (1994) The CCP4 suite: programs for protein crystallography. Acta Crystallogr D: Biol Crystallogr 50:760-763

Emsley P, Cowtan K (2004) Coot: model-building tools for molecular graphics. Acta Crystallogr D: Biol Crystallogr 60:2126-2132

Fukao T, Song XQ, Mitchell GA, Yamaguchi S, Sukegawa K, Orii T, Kondo N (1997) Enzymes of ketone body utilization in human tissues: protein and messenger RNA levels of succinyl-coenzyme A (CoA):3-ketoacid CoA transferase and mitochondrial and cytosolic acetoacetyl-CoA thiolases. Pediatr Res 42:498-502

Fukao T, Mitchell GA, Song XQ, Nakamura H, Kassovska-Bratinova S, Orii KE, Wraith JE, Besley G, Wanders RJ, Niezen-Koning KE, Berry GT, Palmieri M, Kondo N (2000) Succinyl-CoA:3-ketoacid CoA transferase (SCOT): cloning of the human SCOT gene, tertiary structural modeling of the human SCOT monomer, and characterization of three pathogenic mutations. Genomics 68:144-151

Fukao T, Shintaku H, Kusubae R, Zhang GX, Nakamura K, Kondo M, Kondo N (2004) Patients homozygous for the T435N mutation of succinyl-CoA:3-ketoacid CoA Transferase (SCOT) do not show permanent ketosis. Pediatr Res 56:858-863

Fukao T, Kursula P, Owen EP, Kondo N (2007) Identification and characterization of a temperature-sensitive $\mathrm{R} 268 \mathrm{H}$ mutation in the human succinyl-CoA:3-ketoacid CoA transferase (SCOT) gene. Mol Genet Metab 92:216-221

Fukao T, Ishii T, Amano N, Kursula P, Takayanagi M, Murase K, Sakaguchi N, Kondo N, Hasegawa T (2010) A neonatalonset succinyl-CoA:3-ketoacid CoA transferase (SCOT)-deficient patient with $\mathrm{T} 435 \mathrm{~N}$ and c.658-666dupAACGTGATT p.N220_I222dup mutations in the OXCT1 gene. J Inherit Metab Dis doi:10.1007/s10545-010-9168-5

Fukao T, Sass JO, Kursula P, Thimm E, Wendel U, Ficicioglu C, Monastiri K, Guffon N, Baric I, Zabot MT, Kondo N (2011) Clinical and molecular characterization of five patients with succinyl-CoA:3-ketoacid CoA transferase (SCOT) deficiency. Biochim Biophys Acta 1812:619-624

Heider J (2001) A new family of CoA-transferases. FEBS Lett 509:345-349

Kassovska-Bratinova S, Fukao T, Song XQ, Duncan AM, Chen HS, Robert MF, Perez-Cerda C, Ugarte M, Chartrand C, Vobecky S, Kondo N, Mitchell GA (1996) Succinyl CoA: 3-oxoacid CoA transferase (SCOT): human cDNA cloning, human chromosomal mapping to $5 \mathrm{p} 13$, and mutation detection in a SCOT-deficient patient. Am J Hum Genet 59:519-528

Longo N, Fukao T, Singh R, Pasquali M, Barrios RG, Kondo N, Gibson KM (2004) Succinyl-CoA:3-ketoacid transferase (SCOT) deficiency in a new patient homozygous for an R217X mutation. J Inherit Metab Dis 27:691-692

McCoy AJ, Grosse-Kunstleve RW, Storoni LC, Read RJ (2005) Likelihood-enhanced fast translation functions. Acta Crystallogr D: Biol Crystallogr 61:458-464

Mitchell GA, Fukao T (2001) Inborn errors of ketone body catabolism. In: Scriver CR, Beaudet AL, Sly WS, Valle D (eds) Metabolic and molecular bases of inherited disease. McGraw-Hill, New York, pp $2327-2356$

Murshudov GN, Vagin AA, Dodson EJ (1997) Refinement of macromolecular structures by the maximum-likelihood method. Acta Crystallogr D: Biol Crystallogr 53:240-255

Niezen-Koning KE, Wanders RJ, Ruiter JP, Ijlst L, Visser G, Reitsma-Bierens WC, Heymans HS, Reijngoud DJ, Smit GP (1997) Succinyl-CoA:acetoacetate transferase deficiency: identification of a new patient with a neonatal onset and review of the literature. Eur J Pediatr 156:870-873

Perrakis A, Harkiolaki M, Wilson KS, Lamzin VS (2001) ARP/wARP and molecular replacement. Acta Crystallogr D: Biol Crystallogr $57: 1445-1450$

Sakazaki H, Hirayama K, Murakami S, Yonezawa S, Shintaku H, Sawada Y, Fukao T, Watanabe H, Orii T, Isshiki G (1995) A new Japanese case of succinyl-CoA: 3-ketoacid CoA-transferase deficiency. J Inherit Metab Dis 18:323-325

Sass JO (2012) Inborn errors of ketogenesis and ketone body utilization. J Inherit Metab Dis 35:23-28

Snyderman SE, Sansaricq C, Middleton B (1998) Succinyl-CoA:3ketoacid CoA-transferase deficiency. Pediatrics 101:709-711

Solomon F, Jencks WP (1969) Identification of an enzyme-gammaglutamyl coenzyme A intermediate from coenzyme A transferase. J Biol Chem 244:1079-1081

Song XQ, Fukao T, Watanabe H, Shintaku H, Hirayama K, Kassovska-Bratinova S, Kondo N, Mitchell GA (1998) Succinyl-CoA:3-ketoacid CoA transferase (SCOT) deficiency: two pathogenic mutations, V133E and $\mathrm{C} 456 \mathrm{~F}$, in Japanese siblings. Hum Mutat 12:83-88

Tanaka H, Kohroki J, Iguchi N, Onishi M, Nishimune Y (2002) Cloning and characterization of a human orthologue of testis-specific succinyl CoA: 3-oxo acid CoA transferase (Scot-t) cDNA. Mol Hum Reprod 8:16-23

Williamson DH, Bates MW, Page MA, Krebs HA (1971) Activities of enzymes involved in acetoacetate utilization in adult mammalian tissues. Biochem J 121:41-47

Yamada K, Fukao T, Zhang G, Sakurai S, Ruiter JP, Wanders RJ, Kondo N (2007) Single-base substitution at the last nucleotide of exon 6 (c.671 G>A), resulting in the skipping of exon 6 , and exons 6 and 7 in human succinyl-CoA:3-ketoacid CoA transferase (SCOT) gene. Mol Genet Metab 90:291297 